\title{
Cartas, indagações e estudos sobre a África centro-ocidental e os Ijebus: a importância dos informantes africanos na produção "científica" francesa na primeira metade do século XIX $^{1}$
}

\author{
Letters, Inquiries and Studies about Central West Africa and \\ the Ijebus: The importance of African informants in French \\ "Scientific" production in the First Half of the Nineteenth Century
}

Aderivaldo Ramos de Santana*

Resumo: Um estadista brasileiro que, no inicio do século XIX, deduz o curso do rio Níger a partir do interrogatório que realizou com alguns escravos africanos no Brasil; um naturalista que, seguindo o mesmo método, pretendeu fazer uma síntese de tudo o que se conhecia sobre a África centro-ocidental, utilizando como seus informantes, africanos haussas escravizados em Salvador da Bahia; um homem de "ciência" que, durante a Corte de Louis-Philippe, realizou um estudo sobre o reino Iorubá, recorrendo as informações de um africano ijebu, que havia sido escravo no Brasil e residia em Paris na condição de homem livre. Esses são alguns exemplos de uma história da África elaborada a partir de relato de africanos escravizados. O presente artigo pretende demonstrar de que maneira, durante a primeira metade do século XIX, a utilização de informantes africanos como fontes orais, por parte das sociedades científicas, tiveram um papel de extrema importância na produção de conhecimento sobre o interior do continente africano, sobretudo numa fase preparatória à colonização europeia.

Palavras-chave: História da África, Tráfico transatlântico de escravos, Biografia de escravos, Sociedade de Geografia de Paris,

\footnotetext{
Abstract: A Brazilian statesman who, in the early nineteenth century, deduced the course of the Niger using the interviews that he made to some African slaves in Brazil; a naturalist who, following the same method, tried to summarize

(c) BEY Direito autoral e licença de uso: Este artigo está licenciado sob uma Licença Creative Commons. Com essa licença você pode compartilhar, adaptar, para qualquer fim, desde que atribua a autoria da obra, forneça um link para a licença, e indicar se foram feitas alterações.
} 
all what was known about Central West Africa, using as informants, African Haussas enslaved in Salvador da Bahia; a man of "Science" who, during the Louis-Philippe Court, made a study of the Yoruba kingdom, using the information from an African Ijebu, who had been a slave in Brazil and resided in Paris as a free man. These are some examples of a Africa History elaborated from some enslaved Africans' accounts. This article pretends to show how, in the first half of the 19th Century, the use of African informants as oral sources by scientific societies played at extremely important role in the production of knowledge about the interior of the African continent, during the planification for European colonization.

Keywords: Africa History, Brazilian Slave-Trade, Slaves Narratives, Geographical Society of Paris.

\section{Introdução}

O estadista José Bonifácio de Andrada e Silva deduziu, no início do século XIX, o curso do rio Níger a partir do interrogatório que realizou com alguns escravos africanos no Brasil. No final dos anos 1840, o naturalista francês Francis de Castelnau, seguindo o mesmo método de José Bonifácio, pretendeu fazer uma síntese de tudo o que se conhecia sobre a África centro-ocidental utilizando como seus informantes alguns africanos haussas, escravizados em Salvador da Bahia. No mesmo período, o vice-presidente da sociedade de Etnologia de Paris Marie Armand d'Avezac realizou um estudo sobre um dos subgrupos iorubás do Sudeste da atual Nigéria, recorrendo as informações de um africano ijebu que havia sido escravo no Brasil e que residia em Paris na condição de homem livre. Esses são alguns exemplos de uma história da África elaborada por homens de ciência, por membros de Sociedades Científicas do século XIX, a partir dos relatos de africanos, na condição de escravos ou libertos. A análise desses relatos, confrontados com pesquisas contemporâneas nos permite inseri-los numa perspectiva historiográfica que privilegia o protagonismo e a capacidade de "agir" de indivíduos pertencentes as classes marginalizadas. Assim sendo, o estudo do que eles sabiam, de seus conhecimentos sobre suas regiões e população, nos permitem compreender como esses indivíduos, de maneira direta ou indireta, influenciaram o rumo da história. ${ }^{1}$

O presente artigo pretende demonstrar como a utilização de informantes africanos, na condição de fontes orais, por parte das sociedades científicas do Velho Mundo, tiveram um papel de extrema importância na produção de conhecimento sobre o interior do continente africano, numa fase preparatória à colonização europeia. ${ }^{2}$ Compreender de que maneira esses indivíduos serviram 
de objeto de investigação "científica," também nos permitem identificar um volume considerável de documentos úteis aos estudos que visam reconstituir e trazer à tona biografias inéditas de africanos escravizados no Brasil. Cabe ainda ressaltar que essas entrevistas, realizadas com a finalidade de conhecer o interior da África subsaariana, nos oferecem elementos-chave de extrema importância para compreendermos as subjetividades escravas, sobretudo a partir da experiência do cativeiro e da liberdade. Nesse sentido, dividimos nossa exposição em quatro partes. Buscamos num primeiro momento contextualizar, através do surgimento das sociedades científicas, o período histórico no qual esses africanos foram entrevistados. É evidente que essas instituições não se interessavam somente em conhecer o interior do continente africano. Porém, tendo em vista a extensão desse território e da possibilidade de exploração econômica que ele representava, a África se tornou o centro de interesse dos que pretendiam contribuir para o progresso da civilização. Depois dessa primeira parte, buscamos analisar, de maneira objetiva, cada um dos três documentos por nós escolhidos - divididos em uma secção cada -, evidenciando o papel relevante que os africanos entrevistados tiveram na produção de conhecimento sobre suas regiões. Tentamos completar essa análise, dialogando com outros estudos contemporâneos de forma a inserir essas entrevistas no contexto global do tráfico transatlântico de escravos para o Brasil e o estudo das biografias de escravos, um dos nossos centros de interesse e atual pesquisa de doutoramento.

\section{As Sociedades Científicas na França e o seu interesse no interior do continente africano no início do século XIX.}

“Voir c'est avoir; allons courir!" (Ver é possuir, então vamos correr!) Esse verso do poema "Les bohémies » de Pierre-Jean de Béranger, ${ }^{3}$ traduz com maestria o espirito de um tempo onde era necessário percorrer o mundo, saber de tudo e viver intensamente. De um tempo no qual ocupar passou a significar possuir. Marcada pelo romantismo, a França do início do século XIX era o segundo país mais populoso da Europa, onde os proprietários e nobres dominavam a massa camponesa. Assim como em Inglaterra, somente os mais abastados podiam lançar-se em viagens através do continente europeu e até mesmo percorrer o mundo. A influência romântica também foi responsável pela criação das Sociedades Científicas, cujos representantes da elite podiam compartilhar as impressões e experiências de suas expedições exploratórias. ${ }^{4}$

Cabe lembrar que no início do século XIX, o conceito de ciência não corresponde ao conceito positivista pelo qual ela é conhecida atualmente. Foi justamente durante esse século que a ciência e o fazer científico sofreram uma mudança radical de significação. Ela deixou de designar todo conhecimento do tipo universitário, constituído em disciplina e passou a estar associada as atividades desenvolvidas dentro dos laboratórios, dos observatórios astronômicos, associada a matemática e comumente chamadas de ciências 
exatas. Dito isso, a utilização do termo ciência/científico(a) no presente artigo, reconhece uma concepção mais ampla, na qual o mesmo designa todo e qualquer estudo sistemático, associado a ideia de progresso. Para as ditas Sociedades Científicas e seus membros, a ciência era uma prática humana, correspondente ao desejo de saber, do qual o progresso era indissociável. ${ }^{5}$

Nessa época multiplicaram-se o número dessas associações por toda a Europa ${ }^{6}$ Em Paris, a Sociedade de Geografia foi criada em 1821, ${ }^{7}$ a de Etnologia em 1838. Em Berlim, a Sociedade de Geografia se reuniu pela primeira vez em 1828, enquanto a de Londres abriu suas portas dois anos mais tarde. Todas tinham como objetivo principal manter, entre seus associados, um conhecimento do mundo, o mais atualizado possível, e assim poder contribuir para o progresso de cada nação, tudo em nome da ciência. Para tal, eles acolhiam um número significativo de narrativas de viagens e até mesmo estudos realizados por simples curiosos. Suas reuniões e encontros anuais correspondiam a parte mais interessante do trabalho dos que se autodominavam naturalistas, etnólogos, antropólogos e geógrafos no sentido etimológico do termo, à saber: aquele que descreve a terra. Além de membros dessas Sociedades Científicas, alguns desses homens eram representantes do poder públicos, professores das escolas politécnicas, observatório, museu, faculdades e alguns funcionários da administração francesa, como por exemplo o ministério da marinha e das colônias.

Apaixonados pelo progresso científico, eles faziam parte do que Angel Rama caracterizou como a "cidade das letras"s e, em geral, essas agremiações consagravam suas reuniões, entre outros temas, a descoberta da parte subsaariana do continente africano, considerada terra nondum cógnita. ${ }^{9}$ Assim, desde 1788, a Royal African Society de Londres tinha como objetivo "a exploração do Oeste africano, em particular a descoberta da fonte do rio Níger e a cidade de Tombuctu." ${ }^{10}$ E não tardou muito para que as outras Sociedades Científicas seguissem o exemplo. E nessa busca por percorrer o interior da África, em nome da ciência, a França saiu na frente. Em 1830, a Sociedade de Geografia de Paris editou o que se tornaria um verdadeiro sucesso na época, a narrativa de viagem de René Caillé "Journal d'um Voyage à Temboctou et à Janné, dans l'Afrique Centrale." Caillé permaneceu treze dias na cidade misteriosa, como era chamada Tombuctu, e foi primeiro viajante europeu a retornar com vida. O major inglês Alexander Gordon Laing ${ }^{12}$ foi assassinado quando regressava de sua expedição à Tombuctu em 1826. Somente o alemão Heinrich Barth teve acesso aos manuscritos de cidade misteriosa, que ele traduziu durante sua expedição em $1854 .{ }^{13}$

No final do século XIX, em razão de todas essas iniciativas impulsionadas pela "volonté de savoir" (vontade de saber), ${ }^{14}$ podemos considerar que existiam poucos territórios no mundo a serem "descobertos". Porém, cabe lembrar que, num primeiro momento, a busca por informações sobre o interior do continente 
africano se fez em estreita colaboração entre: membros de Sociedades Científicas, viajantes e exploradores independentes, oficiais a serviço dos diversos governos, missionários católicos, sem que os interesses nacionais entrassem em conflito. ${ }^{15}$ Vejamos como isso ocorreu.

Devido aos trabalhos realizados por alguns dos membros da Sociedade de Geografia de Paris, a África, tida na época como terra "inóspita," se tornou cada vez mais acessível, se "revelando" mais e mais a exploração investigativa. ${ }^{16}$ De fato, cada oficial que partia em missão contatava com os "especialistas" membros das Sociedades Científicas para pedir maiores informações que poderiam ser uteis durante sua viagem. No caso especifico dos geógrafos de Paris, eles eram representados principalmente por Charles Athanase Walkenaer, Edme-François Jomard e Marie-Armand Pascal d'Avezac, que recebiam a maior parte das correspondências enviadas por expedicionários. Eles também preparavam alguns questionários destinados aos oficiais para que buscassem completar o quadro de informações que se tinha sobre as regiões à serem exploradas. Uma vez na África, esses oficiais se tornavam correspondentes diretos das Sociedades Científicas, enviando cartas que eram lidas publicamente aos associados que participavam das reuniões mensais. As informações dos expedicionários eram traduzidas e publicadas nos boletins das associações francesas e vice-versa.

Foi assim que em 1837, d'Avezac comunicou aos membros da Sociedade de Geografia sobre a morte do viajante inglês John Davidson, assassinado na estrada à vinte sete dias da cidade de Tombuctu. ${ }^{17}$ É também através dessas comunicações que podemos identificar como, pouco a pouco, essas associações passaram a utilizar o testemunho oral de africanos para preencher o que se faltava saber sobre o interior do continente. ${ }^{18}$ Alguns desses muitos informantes africanos foram levados para França, outros foram interrogados no Brasil e seus testemunhos conferiam autoridade aos relatos dos viajantes. Em 1839, Edme-François Jomard leu parte de uma carta enviada por seu correspondente, Antoine d'Abbadie, enviado à Malta, em janeiro do mesmo ano, rumo à Abissínia. Abbadie afirma levar para França dois indivíduos "um galla e um abissínio" capazes de conversar entre eles cada um na sua língua, confirmando assim as considerações "etnográficas sobre a África Oriental" deduzidas a partir, simplesmente, do aspecto físicos desses habitantes. ${ }^{19}$ Galla era como ficaram conhecidos os atuais oromos da África do Leste, que vivem na região da Oromia, na Etiópia. ${ }^{20}$ Quando chegou em Paris, Abbadie leu um resumo de sua viagem e apresentou os dois africanos que havia trazido consigo. O abissínio chamava-se Gebra Oezziabher, membro de uma das principais famílias de seu país e o jovem galla se chamava Gabao, que Abbadie havia comprado para ensiná-lo "as primeiras letras" e, posteriormente enviá-lo a seu país como missionário da "civilização." ${ }_{21}$ Assim sendo, fica evidente que alguns desses africanos trazidos para a Europa tiveram uma dupla função, 
foram valiosos informantes, revelando com precisão suas regiões e também serviram de aliados dos europeus no processo de colonização.

Pesquisar quem eram esses africanos e de onde viam tornou-se a razão de ser dessas associações que construíram, progressivamente, uma ideia da origem do rio Níger, da cidade de Tombuctu e das populações que viviam nessas partes do continente africano, tidas como desconhecidas. Ainda em 1839 , Jomard anunciou a seus pares que ele se tornaria o tutor de um outro jovem galla chamado Ouaré, nativo do país Limmou. Nascido em Sobitché, filho de um "guerreiro temido" e um "rico proprietário de gado." ${ }_{22}$ Um vez em Paris, Ouaré contou a Jomard como se tornou escravo. Ele foi sequestrado por traficantes quando estava sozinho no campo, longe de seus irmãos e de seu pai que havia permanecido em casa porque estava doente. Os traficantes de escravos o levaram, junto com outros trinta jovens de ambos os sexos, a um mercado na cidade de Cartum, capital do atual Sudão. A caravana percorreu uma distância de quatro meses de caminhada. Durante a longa viagem, vinte jovens morreram. Chegando ao mercado, ele foi comprado por um inglês que o libertou e cuido dele por algum tempo. Embora liberto, Ouaré era ainda uma criança e sua existência dependia de outrem. Quando se separou do inglês, que havia sido seu primeiro e único proprietário, Ouaré passou dois anos servindo a um chefe do exército egípcio até que esse último o levou para França onde ele deveria receber "educação." ${ }^{23} \mathrm{O}$ relato do jovem africano é um dos raros testemunhos do tráfico interno de escravos, do qual existe pouca documentação. ${ }^{24}$

Por tudo que contou sobre a geografia e a cultura do seu país, Ouaré assim como outros africanos interrogados pelos membros da Sociedade de Geografia de Paris, tornaram-se fontes orais de máximo valor. ${ }^{25}$ Entretanto, Walkenaer, Jomard e d'Avezac não foram os únicos que se serviram dos conhecimentos dos informantes africanos. Os viajantes europeus conversavam e dependiam dos autóctones, quer fossem eles escravizados ou libertos, conferindo-os extrema credibilidade. Quando, por exemplo, surgiram dúvidas, entre os membros das sociedades científicas, sobre a viagem de Renné Caillé, o reverendo Renouard, membro da Sociedade de Geografia de Londres, enviou uma carta a Jomard para apresentar seu apoio e poder, de alguma forma, "vingar" a honra do viajante francês, sobretudo após as duras críticas que foram publicadas na Quartely Review, pretendendo desqualificar a expedição de Caillé. Na sua correspondência, Renouard afirmou ter examinado o resultado do itinerário descrito por Caillé e atestou sua veracidade. Isso porque a maioria dos "países" (regiões) mencionados pelo viajante francês, não eram desconhecidos do africano Abou-Bekr, entrevistado pelo reverendo e cuja história pessoal foi impressa no jornal da Sociedade de Geografia de londrina em 1836. ${ }^{26}$

É com base nesse critério de credibilidade do testemunho oral que o estudo de José Bonifácio de Adrada e Silva, inserido em Lettres sur l'Afrique ancienne et moderne (1826), nos serve como documento primário. Do mesmo 
modo, que o trabalho do Conde Francis de Castelnau: "Renseignements sur l'Afrique centrale et sur une nation d'hommes à queue qui s'y trouverait d'après le rapport des nègres du Soudan, esclaves à Bahia (1851)" e a pesquisa cuidadosa de Jean-Marie Armand d'Avezac "Notice sur le pays et le peuple des Yébous en Afrique (1841)" que permitem, particularmente, ao historiador de hoje, compreender como esses homens de ciência, membros das Sociedades Científicas europeias, conseguiram reunir, na primeira metade do século XIX, informações suficientes sobre uma parte do interior da África. ${ }^{27}$ Do ponto de vista metodológico, esses três documentos nos permitem também sublinhar a relação complexa existente entre o documento escrito e o testemunho oral como o demonstrou Jan Vansina. ${ }^{28}$ De fato, nos casos específicos de transcrição dos interrogatórios, os interrogados podem interromper seus discursos, para retomá-los em seguida, corrigindo-os ou até mesmo modificando-os, o que evidentemente não facilita em nada o trabalho de transcrição do que foi dito e pode interferir na credibilidade e na importância do relato. Mas podemos considerar que o mesmo vale para o documento propriamente escrito como no caso de um diário íntimo que descreve uma intrusão aventurosa à vila mística de Tombuctu. As descrições e os fatos relatados no diário possibilitam a mesma quantidade de interpretações duvidosas. Num caso como no outro, o historiador deve confrontar as informações e cruzá-las com outras fontes, para tentar se aproximar da realidade do ponto de vista histórico.

Comparar os testemunhos orais dos informantes africanos com os registros escritos dos viajantes europeus, os documentos oficiais dos administradores coloniais portugueses, franceses e ingleses nos permite, ainda hoje, estabelecer um quadro amplo das guerras que se produziram no interior da África ocidental e, até mesmo, traçar as rotas utilizadas por traficantes de escravos durante o transporte de cativos do interior até o litoral. $\mathrm{O}$ que escreveram um René Caillié (1830), um Richard Lander (1832) ou um Heinrich Barth (1857) informam ou confirmam as histórias que contaram oralmente de suas capturas e do mundo que até então conheciam um Mohamed, um Aboubakar ou um Osifekunde, e permitem ao historiador compreender o contexto complexo das guerras em território Iorubá. No início do século XIX, informados de tudo o que se publicava até o momento sobre o continente africano e sobre seus habitantes, José Bonifácio, Castelnau e d'Avezac tiveram a oportunidade privilegiada de aprofundar seus conhecimentos sobre algumas das regiões até então desconhecida da maioria dos europeus, norte-americanos e brasileiros.

\section{O interesse de José Bonifácio de Andrada e Silva pelo curso do Níger}

Em 1826, em Paris, Antonio Menezes Vasconcellos de Drummond recebeu de seu amigo, o ex-ministro José Bonifácio de Andrada e Silva, exilado no sul da França, uma correspondência dizendo que tinha determinado o curso 
do Níger. ${ }^{29}$ De fato, depois de interrogar seis africanos haussas, originários da região compreendida atualmente como Níger e Mali, José Bonifácio conseguiu deduzir que na verdade Níger, Joliba, Gulbi e Kwara se tratavam de diferentes nomenclaturas de um único rio. ${ }^{30}$ É importante sublinhar que os haussas entrevistados eram exímios comerciantes inter-regionais, que haviam percorrido quase toda a extensão de seu vasto território.

Esses seis africanos eram apenas uma diminuta parte dos muitos que foram interrogados pelo estadista, especificamente em um estudo que resultou na composição de um mapa do interior do continente africano. Quando ainda era presidente do conselho de ministros do Império, no anos 1820, José Bonifácio entrevistou vários africanos oriundos da região centro-ocidental, para desenhar um mapa “do interior de África, pouco acessível aos europeus." De acordo com François-Eugène Garay de Monglave, que vivia na Corte do Rio de Janeiro, José Bonifácio enviou emissários em uma expedição aos "quatro cantos" do Brasil, sobretudo nas regiões mais afastadas, mandando buscar expressamente "negros vindos da África," de preferência os que sabiam ler e escrever. ${ }^{31}$ Reunirse um número considerável de escravos africanos, que foram separados em grupo de oito a dez pessoas, e interrogados individualmente sobre a geografia de sua terra natal, o nome dos lugares que conheciam, de sua população, seu comércio, as montanhas, os rios, lagos e sobre a topografia das localidades vizinhas. Em seguida, pediu-se para que cada escravo indicasse, entre os outros, aquele cuja terra natal era vizinha da sua. O interrogatório continuava seguindo o mesmo questionário, de modo a completar e interligar os pontos distante de cada região. Um geógrafo assistia tudo, tomando nota e traçando assim os resultados sobre papel, a medida que as respostas eram fornecidas.

Entre os entrevistados estavam: um filho de um rei, um chefe que havia comandado um exercito, um professor de escola corânica, um marabout, infelizes que tinham caído no julgo de um traficante e que foram vendidos a escravidão, deportados para longe da terra que os viu nasceu. Esses indivíduos forneceram informações de interesse do presidente do conselho de ministro do Brasil, informações de uma "exatidão irrecusável," ${ }_{32}$ que serviram para desenhar um mapa detalhado de algumas partes "desconhecidas" do interior da África. Quem eram esses africanos? ${ }^{33}$ E o geografo que "assistia a esse singular congresso de escravos, traçando os resultados sobre o papel"? Essas são algumas das questões que ficaram sem resposta e sobre as quais FrançoisEugène Garay de Monglave não deixou nenhum comentário.

O certo é que, decorre desse experimento as seis valiosas entrevistas que foram publicadas por Menezes de Drummond no texto intitulado "Lettres sur l'Afrique ancienne et moderne." É importante frisas que não existe, nesse texto, menção alguma sobre a religião dos interrogados. Constam somente as rotas principais, os nomes de nações vizinhas e sobretudo localizações que poderiam levar à Tombuctu, que na época era uma das cidades mais 
procurada pelos exploradores europeus, "a pérola do deserto." ${ }^{34}$ Isso porque José Bonifácio, pretendia provar que suas intuições sobre a origem do rio Níger estavam corretas. ${ }^{35}$ Os entrevistados foram descritos com seus nomes cristão, traduzidos para o francês, eram na verdade Francisco, Mateus, José, Bernardo, Bento, Bonifácio, que descreveram suas casas e seus modos de vida, mas principalmente as circunstâncias entre as quais resultaram suas capturas e o itinerário que foram obrigados a percorrer até a Costa dos Escravos, de onde eles foram deportados para o Brasil.

Foi a partir do que disseram esses africanos, em particular os relatos dos escravos Francisco e Bonifácio, que o estadista José Bonifácio concluiu que o rio Níger era o mesmo o Gulbi, do qual falavam esses haussas. ${ }^{36}$ Seguindo o pensamento vigente da época, José Bonifácio também estava interessado no que esses africanos sabiam e disseram sobre a "cidade misteriosa." Para ele, assim como para Menezes de Drummond, seu porta-voz, e para o público em geral, saber onde se localizava e o que havia em Tombuctu era do mais caro interesse. Nesse sentido, o escravo Bonifácio, disse o que muitos esperavam ouvir ao afirmar a existência de minas de ouro. Segundo ele, Tombuctu era uma cidade "considerável, " rodeada de muros, onde "os nobres e ricos iam a cavalo," bem vestidos de camisas brancas ou de nanquim de cor azul, vestimentas de fabricação local..$^{37}$ Francisco, que chegou em Tumbuctu levando uma caravana de 160 camelos, confirmou a existência dos muros altos, fortemente defendidos por artilheiros. Ele também descreveu o comércio dos mouros que trocavam tecidos de linho, seda e algodão, ouro, peças em prata trabalhadas, camelôs, cavalos, escravos, trigo e arroz. ${ }^{38}$

Tudo indica que José Bonifácio procede, como faria um antropólogo, um historiador ou outro pesquisador que, trabalhando com fontes orais, seleciona aquelas informações mais relevante, confrontando-as com mapas e descrições existentes, publicações de outros relatos de viagens. Essas informações o permitem pouco a pouco completar o quebra-cabeça das rotas do tráfico interno de escravos e deduz a origem do rio Níger, cuja configuração particular recebia nomes diferente de acordo com as regiões que ele atravessava, até desembocar num "delta maior que o do Gange." 39

Os seis africanos interrogados por José Bonifácio conheciam bem os territórios que descreveram, e suas descrição não deixaram dúvidas. Antes de se tornar escravo, Francisco percorreu o país Haussa para vender "cavalos, tecidos e escravos." Terminou vítima do comércio, no qual ele era fornecedor. Mateus participou como soldado a invasão da terra dos fulas. Na cidade de Tabarau, José vendia sal, búzios e comprava escravos e algodão. Bernardo também comprava sal dos fulas para revendê-lo mais ao Norte. Somente Bento e Bonifácio foram capturados em suas próprias cidades..$^{40} \mathrm{Uma}$ vez capturados, todos seguiram um longo itinerário, por terra ou em pirogas, que foi minuciosamente anotado e convertido em dias, dias que traduziam distâncias. Para o estadista brasileiro, os 
eventos evocados que resultaram na captura dos seus interrogados eram apenas acessórios. As guerras incessantes a que se dedicavam haussas, o comércio escravo, as condições gerais de existência dos diversos povos mencionados, etc. ${ }^{41}$ Nada parece interessar mais, nem mesmo a condição de escravo de seus informantes, nada além do conhecimento científico parece interessar ao expresidente do conselho de ministro do Brasil, como se o tráfico e a escravidão lhe parecessem como algo normal.

\section{Francis de Castelnau e a ilusão antropofágica}

O caso do Conde de Castelnau é bem diferente do de José Bonifácio. Ele é um naturalista e expedicionário que passou três anos percorrendo algumas cidades da América do Sul, em particular o Rio de Janeiro, Lima e o Pará (1843-1847). ${ }^{42} \mathrm{Na}$ Bahia, como cônsul do governo francês, ele interrogou alguns africanos, motivado pela ambição de também contribuir ao progresso científico e conhecimento da África Central. Desde sua chegada a Salvador da Bahia ele não deixou reparar que alguns dos vários escravos "sabiam ler e escrever o árabe e o líbico," o que lhe seria de extrema utilidade porque eles poderiam fornecer informações sobre as regiões ainda "pouco conhecidas do vasto continente" africano. ${ }^{43}$ Castelneau conseguiu reunir vinte-três africanos e um deles, Mahammah (Manuel de acordo com seu nome de batismo no Brasil) por sua "destacável inteligência," foi escolhido como seu auxiliar e intérprete. Manuel era um ex-soldado de origem haussa, conhecer de algumas das regiões de onde provinham boa parte dos africanos escravos em Salvador. ${ }^{44}$ Por sua posição privilegiada junto ao naturalista, talvez tenha sido proposital a confusão que tenha criado, pois foi justamente Manuel quem induziu Castelnau ao erro de supor a existência de antropófagos, os Niam-Niams, uma suposta tribo de homens com rabo nas montanhas do Bornu.

Castelnau confessou que no início de sua investigação, essa era uma suposição que não mereceu muito interesse. Porém, a teoria ganhou força depois que um outro europeu assumiu ter visto um Niam-Niam durante sua viagem na Arábia ${ }^{45}$ Diante dessa confirmação, o naturalista conferiu maior importância ao tema. O fata é que, analisando o trabalho de Castelnau, fica evidente que dos vinte e três entrevistados, apenas cinco afirmaram ter visto os Niam-Niams com rabo. Entre eles Manuel e Meidassara, que os haviam combatido quando eram soldados no exercito do sultão Kano. Em contrapartida, Mahammah, Karo e Gris, disseram também ter visto os Niam-Niams mas que eles não tinham rabo. Os outros dezoito entrevistados não puderam confirmar se existia ou não uma tribo de antropófagos. Entre esses estava Adamah que foi vendido como escravo para Bahia no final dos anos 1840. Ele, ouviu falar dos "os brancos" e acreditava que eles eram "antropófagos," que compravam escravos para "comêlos." ${ }^{46}$ Nesse enorme patchwork, alguns africanos acreditavam na existência de homens com rabos, os europeus queriam também crê-lo, mas havia aqueles 
que estavam persuadidos que na verdade o antropófago era o homem branco. ${ }^{47}$ $\mathrm{O}$ que podemos apreender com tudo isso é que, talvez sem querer, Castelnau deixa entrever como os jogos de representação intervinham na construção da "historia da raça humana."

Foi assim que Castelnau reanimou uma lenda conhecida desde o século XVIII, sobre a existência de antropófagos homens com rabo. Por sorte e força do debate, essa lenda foi desmentida em 1852 por De Tremaux, que explicou em um artigo publicado no jornal português "O Panorama," ${ }_{48}$ a origem de toda confusão interpretativa. De acordo com De Tremaux, se travava de indivíduos que utilizavam uma casaca feita de pele de animal e que o pequeno rabo era usado como mosquiteiro (espanta mosquito). ${ }^{49}$ Em 1859, Peney que na época era médico chefe do exercito francês no Sudão, também confirmou que não existiam homens com rabo e que o nome Niam-Niam correspondia a onomatopeia de uma tribo de antropófagos. ${ }^{50}$ Sem dúvida, ao contrario do que fez José Bonifácio, Castelnau parecia não ter escolhido seus entrevistados e deixado a porta de sua casa aberta a qualquer indivíduo desde que lhe confirmasse a existência de uma suposta tribo de canibais.

Ainda assim, podemos selecionar informações importante a respeito do continente africano e sobretudo do contexto em que foram escravizados seus informantes. Os africanos interrogados pelo naturalista provinham dos reinos de Kano, Gobir, Katisina, Zaria, Zamfara e Adamawa, que desde 1809 estavam sobre o julgo do sheik fulani Usman Dan Fodio, fundador do Califa de Sokoto. Dan Fodio atacou os reinos de Borno, Nupe e Oyó, numa jihad contra os supostos infiéis que ele vendeu para o comércio trans-saariano e transatlântico. ${ }^{51}$ Quatorze dos entrevistados, de ambos os lados, haviam participado desses combates. Manuel foi capturado quando seu exercito invadiu Borno. Conduzido até a Costa dos Escravos, ele atravessou o território Ioruba até o reino Ijebu, onde foi vendido para traficantes de escravos em Lagos, que em seguida o venderam a um traficante brasileiro. Braz, haussa de Zozo, relatou que combateu contra os soldados de Dammari e de Guari, todos haussas como ele, que tiveram o azar de se revoltar contra o sultão de Sokoto. Mohammad-Abdullah - que não aceita usar seu nome cristão - se tornou prisioneiro à Katsina. Recém deportados como escravos para ao Brasil, Aba-Hama, Solemen e Ali declararam ter sido capturados por correligionários..$^{52}$ Esses africanos que recém-chegados em 1848, nos servem de indícios para afirmar que as guerras, iniciadas no final do século XVIII, continuaram, como se fossem transmitidas de pais para filho ou ao menos de rei para rei. Na época em que Manuel foi capturado, o sultão de Sokoto se nomeava Ali, que era irmão de Atico, filho de Bello, que por sua vez era filho de Osman Dan Fodio, o fundador da dinastia dos fulanis. Nesse contexto, a instabilidade instaurada durante o período das guerras internas na África ocidental favoreceu ao tráfico de escravos transatlântico, sobretudo o comércio negreiro para o Brasil..$^{53}$ 


\section{D'Avezac e os ijebus - a utilidade da fonte oral para o conhecimento dos povos africanos.}

José Bonifácio de Andrada e Silva foi presidente do conselho de ministro do Império do Brasil, Francis de Castelnau era um Conde e naturalista, apreciado pela sociedade parisiense e Marie-Armand d'Avezac de CasteraMacaya pertencia também a essa sociedade. Contrariamente aos dois homens de ciência precedentemente apresentados, d'Avezac não reuniu africanos haussas e nem viajou para desenvolver seus estudos. Como arquivista do ministério da marinha e membro de diversas Sociedades Científicas, ele tinha a sua disposição uma farta documentação, mapas e cartas de correspondentes que exploravam o interior do continente africano. Ademais, o prestigio de sua atividade profissional o oferecia acesso as melhores bibliotecas da época. Ele chegou até a publicar em 1839, uma "relação de viagens de Seawulf à Jerusalem" utilizando um manuscrito da Universidade de Cambridge. ${ }^{54}$ Mas, naqueles tempos, era a África que interessava os estudiosos, membros das já mencionadas sociedades científicas europeias e d'Avezac era, entre seus pares, considerado uma autoridade. Informado de quase tudo, ele foi o primeiro a sublinhar que antes da dupla expedição de Clapperton, José Bonifácio de Andrada e Silva tinha recolhido, no Brasil, informações que "esclareciam" noções sobre os países visitados por Clapperton ${ }^{55}$, D'Avezac não negligenciava a importância do testemunho oral dos autóctones e a necessidade de confrontar esses testemunhos com a bibliografia existente, fazia parte do seu modus operandi. ${ }^{56}$ Foi durante a preparação do seu esboço completo sobre a África que ele encontrou, por acaso, aquele que seria um informante privilegiado, um ijebu que foi escravo no Brasil e tinha se tornado homem livre na França. Esse encontro inusitado fez com que o geógrafo francês pusesse de lado o seu projeto de um esboço sobre o continente africano e decidisse realizar um estudo sobre o país e o povo ijebu, publicado pela primeira vez em 1841 .

No dia 21 de março de 1839, um amigo, cujo nome não foi revelado, apresentou à d'Avezac um africano na esperança que ele o ajudasse a encontrar "meios de retornar ao Brasil." Esse africano era “Ochi-Fêkouè-Dê (Osifekunde), um nativo de ijebu, batizado no Brasil com o nome de Joaquim e conhecido em Paris pelo nome de Joseph." ${ }_{57} \mathrm{Na}$ época, o africano tinha entre 42 e 43 anos, dos quais 17 vividos como escravo no Brasil. Seu segundo proprietário, um comerciante francês residente em Pernambuco, o havia levado à Paris. Como a escravidão era proibida na metrópole francesa, ele conseguiu se tornar homem livre e trabalhar como doméstico num hotel da capital. Chamou à atenção de d'Avezac o interesse do africano em retornar ao Brasil, negligenciando assim a possibilidade real de uma reescravização. Porém, ele conseguiu persuadi-lo a esperar uma oportunidade de repatriamento. Enquanto esperavam, Osifekunde foi trabalhar como doméstico na casa de Vendryès, um francês que no passado havia comercializado com a Jamaica. ${ }^{58}$ Num lugar seguro, o geógrafo passou a 
encontrar o informante e tomar nota de tudo o que seria útil aos seus propósitos de estudo sobre os ijebu, um subgrupo dos iorubás cujo território está situado no Sudeste da atual Nigéria.

Osifekunde parecia não ignorar nada sobre a topografia e geografia de seu país natal. Ele também descreveu aspectos físicos de seus conterrâneos, seus temperamentos, hábitos de trabalho, em particular a fabricação do pano da Costa, cuja recolta, a fiação, a tecelagem e a pintura eram ocupações femininas. ${ }^{59}$ O tempo em que foi escravizado no Brasil não o fizeram esquecer os diversos eventos que marcaram sua existência enquanto ijebu: o ritual do nascimento e a atribuição do nome de batismo, o aleitamento das crianças recém-nascidas, a educação primária, a circuncisão, as tatuagens ou escarificações, casamento, de como os ijebus curavam enfermidades, a expectativa de vida, a morte, os funerais. $\mathrm{O}$ informante parecia ter resposta para todas as perguntas de d'Avezac, que por sua vez indagava sobre como se vestiam, onde residiam, como se alimentavam, sobre quais eram as ocupações domésticas do cotidiano, o que vendiam, qual moeda era utilizada no comércio e como se locomoviam os ijebu, tudo era respondido e com uma extrema precisão. Sobre a moeda, por exemplo, Osifekunde disse que eles usavam os búzios (cauris) e que com 40.000 búzios, o equivalente a 200 francos em 1840, podia se comprar um escravo em Lagos. ${ }^{60}$ Ele narrou aspectos relevantes sobre a vida cultural e religiosa do seu povo, o papel importante que desempenhava a musica, tudo foi descrito com minúcia. Assim como, a organização politica, o sistema judiciário e o funcionamento do exercito, todas essas informações serviram para compor um estudo completo e pioneiro sobre os ijebu.

A partir das respostas de Osifekunde, e reunindo uma vasta documentação sobre à África publicada na Europa, d'Avezac constatou que desde o século XVII, os portugueses reproduziam mapas, tendo como modelo os de Pitolomeu, Livio Sanuto e os atlas de Mercato e Hondius, que incluíam as partes do litoral africano por eles visitadas. Em um dos muitos mapas consultados por d'Avezac, o de Pierre Montier, estabelecia com exatidão o "Rio do Lago" e a cidade de "Jubu" (Jaboo/Ijebu) como denominavam portugueses, holandeses, ingleses e franceses. Porém, d'Avezac não incluiu, em seu inventario de "tudo que tinha sido publicado" sobre a região do Sudeste da atual Nigéria, nem o relato de Duarte Pacheco Pereira "Esmeraldo de Situ Orbis", do final do século XV e inicio do XVI, nem mesmo o relato do capitão Garcia Mendes Castello Branco que visitou a capital do reino Ijebu, a cidade de Ijebu-Ode entre 1621 e $1624 .{ }^{61}$ Pacheco Pereira contou que na cidade de "Hogeebuu" (a capital Ijebu-Ode) existia um comércio de escravos e chifre de elefante. Castelo Branco, por sua vez, disse que o rei de "Xabu", um pequeno reino "extremamente armado, era um amigo dos portugueses," com os quais ele comercializava escravos e tecidos. ${ }^{62}$ Os portugueses tiveram contato com os ijebu antes do que os outros europeus e isso significa dizer que, por mais completo que pudesse ser o 
estudo de d'Avezac, é provável que exista relatos de viajantes portugueses que completariam ainda mais o que disse seu informante africano.

Descendente da família real Ijebu, Osifekunde se dedicava a fazer comércio entre o interior da Iurobolândia e o litoral, onde comerciava com os europeus. Capturado pelos ijos em junho de 1820, ele foi levado para Warri, próximo ao delta do Níger, onde esperou durante quatro dias até ser negociado e vendido a um traficante de escravos brasileiro que o embarcou do porto de Bobi rumo ao Rio de Janeiro. Os ijos eram definidos como "corsários", traficantes que viviam no interior da Guiné, onde se atocaiavam nos bosques e beiras de rios $^{63}$. Na correspondência enviada à Guillaume Bosma, em setembro de 1705, David Nyendall disse que um dos braços do rio Benim levava até a cidade de Warri, na qual os portugueses administravam um entreposto comercial. Nyendall afirmou que os ijos atuavam naquela região e que muitos comerciantes africanos, vindos de Ardra e de Clabary (possivelmente Calabar) eram capturados quando desciam umas das ramificações daquele rio. ${ }^{64}$ Osifekunde esperou quatro dias em Warri, tempo em que durou a negociação entre os ijos e um negreiro brasileiro. Uma vez acertado sua venda, ele foi levado até Bobi (Boobie/Bowbee ou Oubobi), as margens do rio Benim, de onde foi deportado ao Brasil.

Uns dos poucos relatos sobre Bobi são o de William Fitz-William Owen, comandante do navio Leven da Marinha inglesa, que tinha por missão explorar toda a costa oriental e ocidental da África. Owen, entrou em Bobi e foi introduzido a Corte do rei Maccaw, que ele descreveu como um "déspota" com modos muito "civilizados" que o ofereceu escravos a baixo custo, ao valor de uma "jaqueta e um par de tesouras" 65 . O baixo valor de compra de escravos deve ter atraído os traficantes brasileiros que se fixaram em Bobi. Em 1837, uma correspondência interceptada pelo Foreign Office inglês, depois da captura do navio negreiro Camões, descrevia a existência de uma sociedade composta por traficantes de escravos africanos e brasileiros estabelecidos dos dois lados do Atlântico, cuja sede estava baseada no Recife. ${ }^{66}$

De acordo com o que publicou d'Avezac, Osifekunde foi vendido para o Rio de Janeiro e, depois de ter um primeiro proprietário, se tornou escravo doméstico de um negociante francês chamado Navarre. Em 1837, esse negociante o levou à Paris, onde ele se tornou homem livre de "pleno direito" e foi durante seus primeiros anos na França que ele conheceu o geografo d'Avezac e o serviu de objeto científico. Após quatro anos na capital francesa, Osifekunde negociou melhores condições de trabalho e decidiu voltar para o Brasil, para trabalhar com Navarre.

\section{Conclusão}

No final do século XIX, o médico e antropólogo Raimundo Nina Rodrigues justificava a pertinência de seu estudo sobre os africanos e seus 
descendentes no Brasil, citando um fragmento do texto "A poesia popular no Brasil" de Silvio Romero, publicado em 1879. Em seu texto, Romero denunciava o pouco interesse dos brasileiros pelas línguas e culturas africanas. ${ }^{67}$ Porém, é provável que Romero e até mesmo Nina Rodrigues desconhecessem o estudo pioneiro de José Bonifácio sobre o interior do continente africano, a partir dos interrogatórios realizados no início do mesmo século. Certamente porque esse estudo nunca foi publicado no Brasil, nem mesmo depois que o estadista retornou do exílio. Em contrapartida, as entrevistas dos seis haussas foram importantes para os exploradores europeus.

De fato, temos todas as razões para acreditar que a "pesquisa minuciosa," coordenada por José Bonifácio, a partir das entrevistas com africanos, fazia parte de um estudo cujo objetivo estava diretamente relacionado a um investimento brasileiro numa possível colonização africana. Depois de mais de dois séculos os brasileiros comercializavam com a outra margem do Atlântico e a independência do Brasil, em 1822, foi imediatamente reconhecida por alguns Estados africanos como o Dahomé, passível de se tornar um protetorado brasileiro. Podemos supor então, que José Bonifácio pensava em anexar colônias africanas ao futuro Império brasileiro, uma intenção que, diga-se de passagem, foi imediatamente proibida pelo acordo luso-brasileiro de $1826 .{ }^{68}$ O método utilizado por ele para conseguir informações sobre as possíveis futuras colônias era inovador, como sublinhou Eugène Garay de Monglave, quando fez questão de sugeri-lo como modelo a seguir. Monglave desejava que os franceses fizessem o mesmo que fez José Bonifácio, desejo que deveria ser perseguido por todos os governos que ainda possuíssem escravos "vindos diretamente da África," para que eles pudessem empreender estudos a partir de entrevistas/interrogatórios com africanos, entrevistas que poupariam as vidas dos viajantes europeus que se aventuravam em explorar o que eles consideravam como terra inóspita. ${ }^{69}$

Foi assim que, durante todo o século XIX, os informantes africanos, principalmente aqueles que sabiam ler e escrever - no caso dos islamizados passaram a ser respeitados por naturalistas, etnólogos e geógrafos franceses, os quais as Sociedades Científicas disputavam o resultado de suas entrevistas e estudos. Acabamos de observar três desses estudos realizados a partir da mesma metodologia, onde o testemunho oral era parte essencial do trabalho de pesquisa. O Modus Operandi utilizado por esses homens de ciência, ainda incluía desenhos de mapas, retratos dos entrevistados e, o mais importante, um vocabulário comparativo dos diversos idiomas por eles utilizados. José Bonifácio separou apenas seis dos seus entrevistados sudaneses que se tornaram mercadorias do tráfico negreiro. Ele anotou o itinerário que eles tiveram que seguir do interior até a Costa, de caminhada forçada ou em piroga, tudo foi escrupulosamente anotado e calculados em dias. Esses dias de viagem foram traduzidos em distâncias, que o possibilitaram determinar, de maneira objetiva, 
os resultados equivalentes aos publicados depois das expedições realizadas no interior do continente africano pelo major Hodgson em 1791, a de Mungo Park em 1795 e 1806. Quando escreveu as cartas enviadas a seu amigo Menezes de Drummond, José Bonifácio não deixou de incluir no resultado dos seus interrogatórios, as descobertas recentes de Giovanni Battista Belzoni, que havia falecido em Gwato, Hugato ou Ughaton no reino do Benim (atual Nigéria), quando pretendia subir o rio Joliba ou Níger pelo delta. ${ }^{70}$ As observações de Belzoni corroboravam com as que o estadista brasileiro havia coletado da boca dos africanos no Brasil. Porém, foi necessário esperar o ano de 1832 e a publicação do "Journal d'une expédition entreprise dans le but d'explorer le cours et l'embouchure du Niger" dos irmãos Richard e John Lander para que os trabalhos de José Bonifácio e Belzoni fossem caucionados. ${ }^{11}$

Ainda que menos eficaz, o estudo do Conde de Castelnau utiliza a mesma metodologia empregada por José Bonifácio. Porém, parece que a maioria dos 23 indivíduos que ele entrevistou estavam mais interessados no que o francês poderia oferecer (bebida, alimentos e até mesmo dinheiro). Podemos quase visualizar esses africanos, observando o científico "branco" trabalhar, inventando uma teoria para justificar a inferioridade do homem africano. ${ }^{72}$ Lendo o trabalho de Castelnau, temos a impressão que ele é menos formal do que José Bonifácio e que, por alguns instantes, os informantes parecem escapar as suas condições cotidianas de escravos, enquanto ele - homem de ciência - não perde uma só palavra do que foi dito, sem ao menos se dar conta de que -às cegas - acaba acreditando em tudo que os africanos relatam. No que diz respeito a relação entre d'Avezac e Osifekunde, ela é humana ainda que ambígua. $\mathrm{O}$ cientifico se entristece de perder seu providencial informante ijebu, porque lhe parece inconcebível que o africano queira retornar ao país onde fora escravizado. Porém, para Osifekunde, nada vale mais no mundo do que estar entre os seus no Brasil.

As circunstâncias em que os indivíduos, aqui apresentados, foram capturados, correspondem aos recorrentes episódios de conflitos no interior do continente africano, sobretudo depois da queda do Império Oyó. Conflitos que deram origem a novos centros políticos na primeira metade do século XIX. Alguns desses centros políticos, como o reino Ijebu, se constituíram como potentes comerciantes de escravos. Nesse sentido, a mobilidade quer fosse individual ou coletiva, era exercida em conformidade com os controles de fronteiras e relações comerciais reciprocas que podiam ser alteradas num piscar de olhos e para se transitar em segurança, era preciso estar a par da situação politica de cada cidade, do surgimento de novas rotas, da mudança de chefia e das convenções sociais, que foram literalmente destruídas depois do início desses conflitos. Diante desse contexto, como bem salientou Camille Lefebvre, o próprio movimento de ir e vir era determinado pela posição social de cada individuo. ${ }^{73}$ 
Para as Sociedades Científicas, que pretendiam somente tirar proveito dos conhecimentos que tinham esses africanos a respeito do mundo dito "desconhecido," as circunstâncias de suas capturas e mesmo a dura realidade da escravidão não tinham tanto interesse. O que essa "cidadela letrada" desejava era, de uma parte, para civilizá-los e de outra, cooperar com a empresa colonizadora europeia em África. Para tal, nos seus boletins e jornais, essas sociedades publicaram as atas de suas reuniões e também as indicações, conselhos, as discussões sobre os diferentes temas que eram abordados, diretamente ligados ao progresso da ciência e as descobertas no continente "negro". A esse material, ainda eram acrescentadas as traduções de textos de outras sociedades, em particular os textos em inglês, e dessa maneira os membros franceses puderam seguir atualizados, a partir das descobertas cientificas de outras nações. Foi graças à essas publicações que a população alfabetizada $\mathrm{e}$ não associada pôde estar a par do progresso científico. E foi sobretudo graças aos informantes africanos, que esses homens de ciência e alguns intrépidos exploradores tiveram acesso a geografia detalhada do Niger, um dos maiores rios da África, confirmaram a localização de Tumbuctu, conheceram a língua ioruba dos ijebu e os costumes de alguns povos da parte ocidental. Ainda não sabemos se d'Avezac pretendia fazer de Osifekunde um aliado nessa empreitada colonizadora e por isso insistia tanto para que ele voltasse para sua terra natal. O que sabemos é que, para o historiador de hoje, que se interessa pela história do continente africano, os documentos analisados no presente artigo servem, de modo geral, como fontes importantes para compreendermos a origem da boa parte dos mais de 4.000.000 de indivíduos que foram deportados como escravos para o Brasil.

\section{Notas}

* Doutorando de História Contemporânea - Universidade Paris IV -Sorbonne. Paris, França. E-mail: derisantana@gmail.com

$1 \mathrm{Um}$ dos principais expoentes dessa metodologia de análise de uma história « par le bas » (History from below) foi Edward Thompson. Thompson, Chirstopher Hill, Rodney Hilton e Eric J. Hobsbawm entre outros, faziam parte de um grupe de historiadores do partido comunista (Communist Party Historians group) interessados em romper com o conservadorismo dominante no meio acadêmico. Foi esse grupo de historiadores que criaram, em 1952, a revista Past and Present, e contribuíram para renovar a história social e política na Inglaterra. Cf. THOMPSON, Edward. P. :, A formação da classe operária inglesa, 1: a árvore da liberdade, Rio de Janeiro: Paz e Terra, 2011; Nos Estados Unidos, o maior representante desse movimento é o historiador Howard Zinn, seguido por Marcus Rediker. Ambos demonstram que não se trata simplesmente de fazer uma história dos pobres e da classe operária, mas demonstrar como a "agência" particular desses indivíduos influenciou o rumo da história. Cf. ZINN, Howard; KONOPACKI, Mike; BUHLE, Paul, A people's history of American empire: a graphic adaptation, 1st ed. New York: Metropolitan Books, 2008; REDIKER, Marcus, The slave ship: a human history, New York: Viking, 2007; REDIKER, Marcus; BLANCHARD, 
Aurélien, Les révoltés de l'Amistad: une odyssée atlantique, 1839-1842, Paris: Éditions du Seuil, 2015; REDIKER, Marcus; BLANCHARD, Aurélien, Les hors-la-loi de l'Atlantique: pirates, mutins et flibustiers, [s.1.: s.n.], 2017.

2 Sílvio Marcus de Souza Correa demonstrou como missionários e naturalistas valiam-se de saberes locais para produzir conhecimento sobre os trogloditas e sobre o interior do continente africano, destacando o papel importante dos africanos para a produção científica e literária do século XIX. Cf. CORREA, Sílvio Marcus de Souza. A "partilha do Gorila” entre ciência e literatura de alhures e saberes locais. In Historia: Questões \& Debates, Curitiba, volume 62, $\mathrm{n}^{\circ}$ 1, p. 107-132, jan./jun. 2015. Editora UFPR.

3 DE BÉRANGER, Pierre Jean, Oeuvres complètes, [s.1.: s.n.], 1838, pp. 359-361. O poema de Béranger também foi utilizado como epígrafe para o livro do explorador francês René Caillé sobre sua viagem à Tombuctur.

4 Os parágrafos subsequentes baseiam-se principalmente nos boletins das Sociedades de Geografia de Paris e Londres, durante os anos 1820 e 1850, disponiveis no site da Biblioteca Nacional de França - BNF. http://gallica.bnf.fr , em googlebooks http://books.google.fr e archives.org http://archives.org acessados no entre 2010 e 2015.

5 Sobre a evolução do conceito de ciência no século XIX, principalmente na América do Norte. Cf. TURNER, James M. Le concept de science dans l'Amérique au XIXè siècle. Annales. Histoire Sociales, 2002/3 (57e année), p. 753-772.

6 No caso da França, o artigo 300 da Constituição de 1795 dava o direito aos cidadãos que quisessem fundar estabelecimentos privados de educação e instrução, assim como as associações que pretendessem contribuir para o progresso das ciências, letras e artes. De modo que no final do século XIX, existiam em Paris 360 Sociedades Científicas e mais de 600 nas demais regiões da metrópole.

7 Para um estudo completo sobre a Sociedade de Geografia de Paris, ver : D. LEJEUNE, Les Sociétés de géographie en France, dans le mouvement social et intellectuel du XIXème siècle, thèse doctorale, Paris X, 1987

8 RAMA, Angel, La ciudad letrada, Hanover, N.H., U.S.A.: Ediciones del Norte, 1984.

9 Em abril de 1825, Jomard publicou uma monografia sobre os rios Níger e Nilo. Inserida no caderno de abril de 1825 do boletim da Sociedade de Geografia de Paris, - 1825/01 T3 $\mathrm{N}^{\circ} 21$ - 1825/06 T3 ํ26, p. 257 - Société de géographie (France). Auteur du texte. Bulletin de la Société de géographie (Paris). 1822-1899., disponível em: <http://visualiseur.bnf.fr/ ark:/12148/bpt6k376316>, acesso em: 21 jan. 2016.

10 Ibid. Janeiro e fevereiro ( ${ }^{\circ} 33$ e 34$)$ de 1826, Jomard leu uma nota sumária da relação de viajantes ingleses no interior da África, pg. 475.

11 CAILLÉ, René, Journal d'un voyage à Temboctou et à Jenné dans l'Afrique Centrale. 1a ed 1830., Place of publication not identified: Hachette Livre-Bnf, 2012.

12 Em 1470 Benedetto Dei foi o primeiro europeu a entrar em Tombuctu. Logo depois foi a vez do major Alexander Gordon Laing, que saindo de Trípoli passando por Rhadamès, Salah, Ouallen et Amrennan. Ele foi morto quando retornava pra Europa no dia 24 de setembro de 1826. Seus restos mortais foram descobertos por Bonnel de Mézières em 1920. Cf Colonel Meynier, L'Afrique Noire, Paris, 1921, pg. 189 Apud. L'Exploration du Sahara. In Annales de Géographie, n 266 - Xie année. 15 julho de 1931, pg. 342.

13 Heinrich Barthe foi um geógrafo alemão, poliglota, falando incluso o árabe, idioma essencial para os que se aventuravam no interior do continente africano. Ele viajou por diver- 
sos países do Extremo Oriente e do Norte África, em seguida decidiu empreender algumas explorações desde Trípoli até o Sudão. Realizou um estudo sobre o curso do Níger, depois passou seis meses em Tombuctu, onde traduziu alguns manuscritos para escrever a história do poderoso Império Songhai (Sonhai), Cf. UNIVERSALIS’, Encyclopædia, Heinrich Barth, Encyclopædia Universalis, disponível em: $<$ http://www.universalis.fr/encyclopedie/ heinrich-barth/>, acesso em: 19 jun. 2016.

14 Essa expressão foi usada por Michel Foucault para problematizar o interesse do pesquisador. Cf. FOUCAULT, Michel, La volonté de savoir, Paris: Gallimard, 2001. (a primeira edição é de 1976).

15 Em dezembro de 1831, d'Avezac leu notícias sobre o ataque dos mandingas a um estabelecimento inglês na Gambia, e descreveu como os franceses combateram ao lado dos ingleses pela "causa da civilização." Cf. Société de géographie (France). Auteur du texte. Bulletin de la Société de géographie (Paris). 1822-1899. - n 16 (1831), pp. 281-182

16 Ibid. Julho de 1839, pg. 343.

17 D’Avezac In Société de géographie (France). Auteur du texte. Bulletin de la Société de géographie (Paris) - Janeiro 1837, pg. 274.. John Davidson foi um viajante britânico que se dedicou, a partir de 1827, ao estudo do interior da África. Em 1835, ele tentou entrar em Tombuctu, onde ele foi assassinado no caminho de retorno. Cf. mini biografia de John Davidson (1797-1836), <http://data.bnf.fr/15336398/john_davidson/>, acesso no dia 19 de junho de 2016.

18 Durante sua exploração do interior do continente africano, John Davidson teve o auxílio de um precioso e "inteligente interprete" chamado Abu Bekr, um maometano que tinha vivido durante 20 anos com escravo na Jamaica. Batizado com o nome de Edward Donellan, nome do seu primeiro proprietário, um pedreiro residente na colônia inglesa, Abu Beker teve sua biografia resumidamente publicada no Vol. 6 do Journal of the Royal Geographical Society de Londres. Cf. DAVIDSON, John, Notes Taken During Travels in Africa by the late John Davidson printed for private circulation only, London: J. L. Cox and Sons, 1839. pp, 208-215.

19 Antoine d'Abbadie foi um astrônomo, explorador e linguista francês. Ele foi presidente da Academia de Ciências. Cf. Antoine d' Abbadie (1810-1897), data.bnf.fr, disponível em: $<$ http://data.bnf.fr/13509769/antoine_d_abbadie/>, acesso em: 19 jun. 2016; sobre os dois africanos levados à Paris por d'Abbadie, ver: Société de géographie (France). Auteur du texte. Bulletin de la Société de géographie (Paris). 1822-1899. Julho de 1839, p. 114.

20 Com o tempo, o termo galla se tornou pejorativa. Nesse sentido, o prego do mesmo é somente em respeito a documentação analisada. Atualmente esse grupo étnico é chamado de oromo, que vem de Oromia uma das nove kililoch (região) da Etiópia. Cf. MORIN, Didier, Dictionnaire historique afar: 1288-1982, Paris: Karthala, 2004. pp. 160-162.

21 Société de géographie (France). Auteur du texte. Bulletin de la Société de géographie (Paris). 1822-1899. Julho 1839, p. 253.

22 Ibid., Tomo. 12, p. 6.

23 Ibid. pp. 7-8.

24 Com relação aos africanos que foram vendidos no tráfico negreiro interior, nada sabemos sobre suas experiências pessoais, quando foram capturados, comprados ou vendidos. Assim sendo, devemos valorizar ainda mais suas poucas narrativas existentes. Cf. CONRAD, Robert Edgar, Children of God's fire: a documentary history of black slavery in Brazil, Prin- 
ceton, N.J.: Princeton University Press, 1983,pg. 37-39; A autobiografia de Baquaqua é um dos poucos documentos escritos em primeira pessoa, de um africano que foi capturado no interior e vendido como escravo no Brasil. Baquaqua, originário de Zoogoo, no interior da atual República do Benim, desembarcou numa praia da província Pernambucana na primeira metade do século XIX. Conseguiu escapar de seu segundo proprietário e se tornou homem livre em Nova York, onde publicou sua biografia, considerada o único relato autobiográfico de um africano que foi escravizado no Brasil. BAQUAQUA, Mahommah Gardo; MOORE, Samuel, Biography of Mahommah G. Baquaqua: a native Zoogoo, in the interior of Africa ( convert to Christianity) : with a description of that part of the world, including the manners and customs of the inhabitants ... Mahommah's early life, his education, his capture and slavery in Western Africa and Brazil, his escape to the United States, from thence to Hayti (the city of Port Au Prince) : his reception by the Baptist missionary there, the Rev. W.L. Judd: his conversion to Christianity, baptism, and return to this country, his views, objects and aim, Detroit: Printed for the author, Mahommah Gardo Baquaqua, by Geo. E. Pomeroy \& Co., Tribune Office, 1854; STEIN, Stanley J., Vassouras, a Brazilian Coffee County, 1850-1900: The Roles of Planter and Slave in a Plantation Society, [s.1.]: Princeton University Press, 1985, p. 72; Mbaye Gueye introduz o tema da escravidão e também do tráfico interno no seu artigo, Cf. GUEYE, Mbaye, La traite négrière a l'interieur du continent africain, In La traite négrière du XVe au XIXe siècle, 1979. p. 156-170.

25 Ouaré morreu em Paris no dia 5 de julho de 1841 e Jomard não pode aprofundar, como desejado, sua pesquisa sobre os abissínios.

26 Cf. RENOUARD, G. C. Routs in North Africa by Abu-Bekr es-Siddik, In Journal of The Royal Geographical Society of London, Londres, 1836. In-8 - Tome VI, 1836, pp. 110-113.

27 DRUMMOND, Antonio de Menezes Vasconcellos, Lettre sur l'Afrique ancienne et moderne. In Journal des Voyages, Paris, vol. 32, 1826, pp. 290-324; CASTELNAU, Francis, Renseignements sur l'Afrique centrale, [s.1.: s.n.], 1851; AVEZAC, Armand d', Notice sur le pays et le peuple des Yèbous en Afrique, [s.1.]: Ve Dondey-Dupré, 1845.

28 A utilização de um relato oral não implica necessariamente saber se ele é verdadeiro ou falso. Isso porque, via de regra, o relato dá conta somente daquilo que o interrogado se recorda. No entanto, o historiador deve saber como utilizar esse relato, confrontando-o com outras fontes. Nesse sentido o estudo de Jan Vansina nos serve de modelo. Cf. VANSINA, Jan. De la tradition orale, essai de méthode historique. Musée Royal de l'Afrique Centrale, Tervuren. In Annales Sciences Humaines, ${ }^{\circ}$ A6, 1961.

29 Antonio Menezes Vasconcellos de Drummond ou Menezes de Drummond, como ficou conhecido, foi ministro do Império brasileiro e por seu apoio ao gabinete dos Andradas também foi processado e expulso do Brasil, tendo que se exilar em Paris, onde morreu em 1865. Cf. DRUMMOND, Antonio de Meneses Vasconcelos de, Antações de Vasconcelos de Drummond: à sua biografia, Brasília: Senado Federal, Conselho Editorial, 2012.

30 DRUMMOND, Antonio de Menezes Vasconcellos, Lettre sur l'Afrique ancienne et moderne, pp. 203 e 205.

31 FRANCE, Société orientale de, Revue de l'Orient: bulletin de la Société orientale, Juillet 1857, pp. 268-269. Cf: Gallica, disponível em: <http://gallica.bnf.fr/ark:/12148/bpt6k106667d>, acesso em: 19 jan. 2016.

32 Essas informações constam dos comentários de Garay de Monglave depois da leitura do texto de Menezes de Drummond durante o Terceiro Congresso Anual do Instituto Histórico de Paris, nas seções $5^{\text {a e }} 6^{\text {a }}$, nos dias 15 e 16 de setembro de 1837 . Cf. Revue des études historiques, [s.1.: s.n.], 1837. pp, 241-257. 
33 Quem era o filho do rei africano interrogado por José Bonifácio? Talvez fosse o escravo de ganho que os missionários metodistas Daniel Parish Kidder \& James Cooley Fletcher encontraram carregando café no porto do Rio de Janeiro. Conhecido como "príncipe," ele era - de acordo com os missionários - um membro de uma família real que se tornou escravo depois de perder uma guerra. Reconhecido por seus compatriotas, que ajudaram a comprar sua liberdade e o mandaram de volta para costa africana, onde desafortunadamente ele foi reescravizado e vendido novamente. Cf FLETCHER, D. P. \& KIDDER, J. C., Brazil and the Brazilians, Portrayed in Historical and Descriptive Sketches, [s.1.: s.n.], 1857, p. 135. De fato, entre os milhares de africanos escravizados no Brasil, alguns pertenciam a importantes famílias e outros eram membros de monarquias africanas. Lisa Castillo nos da alguns exemplos no seu artigo sobre Bamboxê Obitikô. Cf. Lisa Castillo, "Bamboxê Obitikô e a expansão do culto aos orixás (século XIX): uma rede religiosa afroatlântica," Tempo, v. 22, n. 39 , p. 126-153, 2016.

34 Em 1825, os ministérios dos negócios estrangeiros e do interior contribuíram financeiramente nas viagens à Tombuctu. Cf. Société de géographie (France). Auteur du texte. Bulletin de la Société de géographie (Paris). 1822-1899. 1826/01 Tomo 3, n $33-1826 / 06$ Tomo 5, $\mathrm{n}^{\circ}$ 38 - documentos e comunicações, prêmio para uma viagem à Tombuctu, p. 211.

35 DRUMMOND, Antonio de Menezes Vasconcellos, Lettre sur l'Afrique ancienne et moderne, p. 205.

36 Ibid, pp. 216-2017.

37 Ibid, p. 211.

38 DRUMMOND, Antonio de Menezes Vasconcellos, Lettre sur l'Afrique ancienne et moderne, p. 212-213. Alberto da Costa e Silva salienta que Leão Africano descreveu a venda de cavalos árabes em Tombuctu, e que em Borno um corcel de raça berbere poderia ser adquirido em troca de 15 a 20 escravos. Dentro da cidade o comércio era exercido por escravos a mando de seus senhores, eles transportavam caravanas, e vendiam comida a mando de seus senhores. Cf Descrição da África, em Giovanni Battista Ramusio, Navigazioni e Viaggi, ed. Org. Marica Milanesi, Turim: Giulio Einaudi, V. 1, 1978 (a primeira edição do volume 1 das crônicas do Leão Africano é de 1550), pp. 387-8, 379 e 386. Apud. SILVA, Alberto da Costa e, A manilha e o libambo: a África e a escravidão, de 1500 a 1700, Rio de Janeiro, RJ, Brasil: Editora Nova Fronteira: Ministério da Cultura, Fundação Biblioteca Nacional, Departamento Nacional do Livro, 2002., pp. 142, 189.

39 DRUMMOND, Antonio de Menezes Vasconcellos, Lettre sur l'Afrique ancienne et moderne, p. 216.

40 Ibid, p. 217.

41 Sobre as disputas envolvendo dissidências muçulmanas no final do século XVIII e inicio do XIX, no chamado Sudão Central, Norte da atual Nigéria, e o tráfico transatlântico que decorreu desses conflitos, ver: REIS, João José, Rebelião escrava no Brasil: a história do levante dos malês em 1835, [São Paulo, Brazil]: Companhia das Letras, 2003. Capitulo 6: Os filhos de Ala na Bahia, pp. 158 - 214.

42 Société de géographie (France). Auteur du texte. Bulletin de la Société de géographie (Paris). 1822-1899. 1851 - Tome $1, \mathrm{n}^{\circ} 1-1851$, Tome $1, \mathrm{n}^{\circ} 6$ - Ouvrages offerts dans la séance de 2 et 16 mai, 6 et 20 juin 1851: Expédition dans les parties centrales de l'Amérique du Sud, de Rio de Janeiro à Lima, et de Lima au Para: exécutée par ordre du gouvernement français, pendant les années 1843 à 1847, sous la direction de Francis de Castelnau - Histoire du Voyage, T. V, in- $8^{\circ}$, Paris, P. Bertrand Editions, 1851. Essa expedição pretendia provar que 
era possível ir das Antilhas francesas até Buenos Aires por via fluvial. Durante essa viagem, Castelnau visitou o Brasil pela primeira vez. Depois da expedição patrocinada pelos Orleans, o naturalista foi enviado ao Brasil como cônsul do governo Francês na província da Bahia.

43 CASTELNAU, Renseignements sur l'Afrique centrale. p. 5.

44 A partir das informações coletadas por Castlenau na Bahia, podemos compreender como seus interlocutores haussas se tornaram escravos, o que parecia não ter muito interesse para o cônsul francês. Portanto, em 1847, seu predecessor, o cônsul Maubuisson escreveu um interessante relatório sobre o tráfico de escravos entre Salvador e Lagos. Compreendendo a importância desse tráfico para economia brasileira, Maubuisson conseguiu investigar, durante um ano, a rota do comércio clandestino de escravos que ligavam o porto bahiano ao porto de Lagos na Costa dos Escravos e forneceu uma lista de traficantes e proprietários de navios negreiros. Cf. Maubuisson: Rapport sur la traite des noirs à Bahia en 1846. $1^{\text {er }}$ mars 1847. Correspondance consulaire et commerciale du Ministère des Affaires Étrangères, vol. 5, Paris. Ubiratan de Castro publicou um excelente artigo na revista Afro-Ásia a partir das investigações de Maubuisson. Cf. ARAÚJO, Ubiratan Castro de, 1846: um ano na rota Bahia-Lagos. Negócios, negociantes e outros parceiro, Afro-Ásia, 1999.

45 Castelnau parece descrever, sem mencionar, o viajante Hornemann que havia citado os Niam-Niams, os quais ele também considerava ser "antropófagos com rabo" Cf. Bulletin de la Société de Géographie, 1852, $4^{\circ}$ série, tomo III, p. 34.

46 CASTELNAU, Renseignements sur l'Afrique centrale. p. 36.

47 Philip Curtin destacou que os africanos muçulmanos do Sudão Ocidental tinham tendência a acusar de canibalismo os povos politeístas, assim como alguns africanos ocidentais acreditavam que os europeus eram antropófagos. Cf. CURTIN, Philip D, Africa remembered; narratives by West Africans from the era of the slave trade, Madison: University of Wisconsin Press, 1967, p. 151; Quando esteve hospedado em um hotel do centro da cidade do Rio de Janeiro, no final da primeira metade do século XIX, F Dabadie viu um escravo "novo," recém deportado, que estava persuadido que iria ser devorado pelos brancos. Cf. DABADIE, F, A travers l'Amérique du Sud, Paris: F. Sartorius, 1858. p. 9.

48 Sociedade propagadora dos conhecimentos uteis (LISBOA), O Panorama, jornal literário e instructivo da Sociedade propagadora, etc. vol. 1-15., O Panorama, jornal litterario e instructivo da Sociedade propagadora, etc. vol. 1-15., 1837. ํ3, agosto, p. 262.

49 Ibid. p. 263.

50 Société de géographie (France). Auteur du texte. Bulletin de la Société de géographie (Paris). 1822-1899. 1859, p. 347.

51 NINA RODRIGUES, Raymundo, Os africanos no Brasil, São Paulo: Madras, 2008. Capitulo II: Os negros maometanos no Brasil, pp. 46-72; VERGER, Pierre, Flux et reflux de la traite des nègres entre le Golfe de Bénin et Bahia de Todos os Santos, du XVIIe au XIXe siècle., Paris; La Haye: Mouton, 1968. Capitulo IX: Révoltes et soulèvements d'esclaves à Bahia, 1807-1835, pp. 325-351; REIS, Rebelião escrava no Brasil. Capitulo 6: Os filhos de Alá na Bahia, pp. 158-214.

\section{CASTELNAU, Renseignements sur l'Afrique centrale.}

53 2.054,726 de africanos desembarcaram como escravos no Brasil entre 1801 e 1850. Esse número representou $42 \%$ do total de 4,8 milhões de africanos deportados do século XVI até 1850. Isso demonstra, por sua vez, como os conflitos no interior do continente, na primeira metade do século XIX, tiveram impacto direto no volume do tráfico transatlântico de escra- 
vos para o Brasil. Esses dados foram computados e estão disponíveis na base de dados: Slave Trade Database www.slavevoyages.org consultado no dia 19 de abril 2008.

54 D'AVEZAC, Armand, Relation des voyages de Seawulf à Jérusalem et en Terre-Sainte pendant les années 1102 et 1103, publiés pour la première fois d'après un manuscrit de Cambridge, [s.1.]: Imp. Bourgogne et Martinet, 1839.

55 CLAPPERTON, Hugh; LANDER, Richard, Second voyage dans l'interieur de l'Afrique depuis le Golfe de Benin jusquà Sackatou., Paris: A. Bertrand, 1829.

56 AVEZAC, Notice sur le pays et le peuple des Yebous en Afrique. introduction : $1^{\text {er }}$ Utilité des informations orales pour la connaissance des peuples africains. pp, 1-7.

57 Ibid.p. 18.

58 Originário de cidade de Bordeaux, Jean-Pierre Firmin Barthélemy Vendryès havia trabalhado para administração colonial na ilha de Guadalupe e possuía uma larga experiência comercial. ADHS - Arquivos e patrimônio_Caixa_DQ14/2002. fl. 79. Registro de falecimento de Jean Baptiste Pierre Firmin Vendryès - 29 de novembro de 1848.

59 AVEZAC, Notice sur le pays et le peuple des Yebous en Afrique, p.76; John Adams que, no início do século XIX, participou de uma expedição que ia do Cabo Palmas até o rio Congo, na qual afirmou que os panos da Costa, vendidos dos portos de Lagos e de Adra para o Brasil, eram extremamente requisitados. O interesse dos traficantes luso-brasileiros nesses tecidos não era somente por sua qualidade, mas pelo significado sentimental do qual eles foram revestidos, tendo em vista que eram fabricados na terra natal de muitos africanos escravizados no Brasil. Adams ainda fez questão de sublinhar que, embora sobretaxados, as importações desses tecidos eram extremamente rentáveis ao comércio português no Brasil. ADAMS, John, Remarks on the Country Extending from Cape Palmas to the River Congo: Including Observations on the Manners and Customs of the Inhabitants ..., [s.1.]: G. \& W.B. Whittaker, 1823. p. 97. Infelizmente não existem estudos que demonstram a importância do pano da Costa e seu impacto na economia brasileira.

60 AVEZAC, Notice sur le pays et le peuple des Yebous en Afrique. p, 78.

61 Ao que tudo indica, d'Avezac não teve tempo de incluir os « detalhes » que expôs o senhor Santarem, um dos membros da Sociedade de Geografia, sobre o manuscrito de Duarte Pacheco Pereira, que foi lido durante a sessão do dia 19 de fevereiro de 1841, da qual d'Avezac participou. Cf. Société de géographie (France). Auteur du texte. Bulletin de la Société de géographie (Paris). 1822-1899. Janeiro 1841, p. 199.

62 PACHECO PEREIRA, Duarte; KIMBLE, George Herbert Tinley, Esmeraldo de situ orbis, [s.1.]: London, Printed for the Hakluyt Society, 1937. p. 71. CASTELLO BRANCO, Garcia Mendes, Relação da Costa d'África, in Luciano Cordeiro, Viagens, explorações e conquistas dos portugueses: Colleção de documentos (6 volumes, Lisboa, 1881), Vol. I. 1574-1620: Da Mina ao Cabo Negro segundo Garcia Mendes Castello Branco, p. 27.

63 BERNEAUD, Arsenne Thiébaut de, Éloge historique de A. M. F. J. Palisot de Beauvois, [s.l.: s.n.], 1821; SILVA, Alberto da Costa e, A enxada e a lança: a África antes dos portugueses, Rio de Janeiro, RJ, Brasil; São Paulo, SP, Brasil: Editora Nova Fronteira; EDUSP, 1992. p. 599-601.

64 BOSMAN, Willem, Voyage de Guinée contenant une description nouvelle \& très-exacte de cette côte où l'on trouve \& où l'on trafique l'or, les dents d'elephant, \& les esclaves: de ses pays, royaumes, \& républiques, des moeurs des habitans, de leur religion, gouvernement, administration de la justice, de leurs guerres, mariages, sepultures, \&c. : comme aussi de la nature \& qualité du terroir, des arbres fruitiers \& sauvages, de divers animaux, tant domes- 
tiques que sauvages, des bêtes à quatre pieds, des reptiles, des oiseaux, des poissons, \& de plusieurs autres choses rares, inconnuës jusques à présent aux Européens, A Utrecht: Chès Antoine Schouten ..., 1705. p, 456.

65 Sobre Bobi como porto do tráfico de escravos, ver: LANDOLPHE, Mémoires du capitaine Landolpe contenant l'histoire de ses voyages pendant trente-six ans, aux cotés d'Afrique et aux deux Amériques; Tome I - p. 160 e Tome II, pp. 30,122 e 343; LEONARD, Peter, The Western Coast of Africa: Journal of an Officer Under Captain Owen. Records of a Voyage in the Ship Dryad in 1830, 1831, and 1832, [s.1.]: EC Mielke, 1833.,pp. 90-113; FAWCKNER, James, Narrative of Capitain James Fawckner Travels on the Coast of Benin, West Africa. Edited by a Frend of the Capitain. London, Published for the Proprietor, by Schloss, 1837, pp. 67,68,107 e 108.; Becroft, "On Benin and the Upper Course of the River Quorra, or Níger. by the Captain Becroft. Communicated by Robert Jamieson, Esq. of Liverpool." The Journal of the Royal Geographical Society of London, volume the eleventh, London. John Murray, Albemarle Street. 1841, pp. 184-190.REIS, João José; GOMES, Flávio dos Santos; CARVALHO, Marcus J. M. de, O alufá Rufino: tráfico, escravidão e liberdade no Atlântico Negro (c. 1822-c. 1853), [São Paulo, Brazil]: Companhia das Letras, 2010. Capitulo 10 : Os patrões de Rufino, pp. 152-174.

66 REIS; GOMES; CARVALHO, O alufá Rufino. Idem, pp. 152-154. Marcus de Carvalho apresentou no $7^{\circ}$ congresso Escravidão e liberdade no Brasil Meridional, em maio de 2015, um estudo aprofundado sobre as atividades dessa sociedade de traficantes de escravos no porto de Bobi. Cf. CARVALHO, Marcus J. M. de, No lado africano do tráfico: trabalho e rotinas de uma feitoria no rio Benim. $7^{\circ}$ congresso Escravidão e liberdade no Brasil Meridional, Universidade Federal do Paraná - Curitiba UFRP, 2015. Anais do evento disponíveis em http://www.escravidaoeliberdade.com.br/

67 Romero, Silvio, “A poesia popular no Brasil”, In Revista Brasileira, 1879, tomo I, p. 99 Apud. Rodrigues, Raymundo Nina, Os africanos no Brasil (São Paulo: Madras, 2008).,pp. 29 et 30 .

Recebido em: 20/12/2017

Aprovado em: 18/02/2018 